\title{
THE ATTEMPTED DEHYDROGENATION OF 3,4-DISUBSTITUTED THIOLANES ${ }^{1}$
}

\author{
ALVIN I. KOSAK ${ }^{2}$ AND ROBERT L. HOLBROOK ${ }^{2}$ \\ Department of Chemistry, The University of Cincinnati, Cincinnati 21, Ohio
}

We have subjected 3,4-thiolanediol and its diester and diethyl ether derivatives to dehydrogenation procedures in an attempt to prepare the corresponding thiophene analogs. Thiolane itself has been dehydrogenated to thiophene in $32 \%$ yield using platinized charcoal at $400^{\circ}$, and in $18 \%$ yield with nickel sulfide on alumina at $350^{\circ}$ (Jurjew and Borissow, 1936); in each case the remainder of the material was converted to hydrogen, hydrogen sulfide, olefins, and alkanes. Passage of thiolane vapors through a "red-hot" glass tube is reported to give traces of thiophene (Grischkewitsch-Trochimowski, 1916). The syntheses of thiophene and its homolgs from hydrocarbons and sulfur probably involve thiolane intermediates which subsequently undergo dehydrogenation (Friedmann, 1951, 1951), and sulfur and thiolane under pressure do give small yields of thiophene (Friedmann, 1951b).

DL-1,4-Dichloro-2,3-dihydroxybutane (Owen, 1949) was cyclized to 3,4-dihydroxythiolane (Kilmer et al., 1942) with sodium sulfide. The latter was converted to the diacetate and dibenzoate esters. The diacetate was also prepared by cyclizing DL-1,4-dichloro-2,3-diacetoxybutane (Owen, 1949). 3,4-Diethoxythiolane was prepared by a slight modification of the method of Patterson and Karabinos (1946).

The four substituted thiolanes were heated with sulfur under dehydrogenating conditions with and without solvents. When short reaction times were employed, most of the starting material was recovered unchanged. Under more vigorous conditions decomposition occurred with the concomitant evolution of hydrogen sulfide. Similar results were obtained using platinum on charcoal as the dehydrogenating agent. Neither of the diesters was attacked by choranil.

In a series of vapor runs, solutions of sulfur and the dibenzoate or the ether were passed under nitrogen pressure through a tube packed with "non-catalytic" fused alumina balls and maintained at temperatures varying from $450-525^{\circ}$. Decomposition occurred in every case. Attempts to split out two molecules of acid from the diester by pyrolysis in the absence of sulfur (Morell et al., 1945; Schlechter et al., 1945) were also unsuccessful.

We believe that dehydrogenation took place during these various experiments, and that the substituted thiophenes then decomposed. The instability of 3,4dihydroxythiophene has been mentioned by Fager (1945) and by Turnbull (1948). The ethoxy, benzoxy, and acetoxy substituents would tend to increase the susceptibility of the thiophene nucleus to degradative attack because of their action in increasing the electron density in the ring.

\section{EXPERIMENTAL}

3,4-Dihydroxythiolane.-The chlorination of butadiene (Mislow and Hellman, 1951) yielded trans-1,4-dichloro-2-butene in $45 \%$ yield (based on butadiene) and

${ }^{1}$ Abstracted from the M.S. thesis of R. L. H., December, 1951. A portion of this material has appeared in Science 0000 .

${ }^{2}$ Present addresses: A. I. K., Department of Industrial Medicine, New York University, New York 16; R. L. H., The Mathieson Chemical Corp., Niagara Falls, N. Y.

The Ohio Journal of Science 53(6): 370, November, 1953. 
$16 \%$ of 1,2-dichloro-3-butene. The former was converted to DL-1,4-dichloro-2,3dihydroxybutane $(56 \%)$ (Owen, 1949), and cyclization to the thiolane was effected by adding a solution of $10 \mathrm{~g}$. (0.04 mole) of sodium sulfide nonahydrate in $5 \mathrm{ml}$ of water to a stirred solution of $4 \mathrm{~g}(0.02$ mole $)$ of dichlorodihydroxybutane in $35 \mathrm{ml}$ of water at $60^{\circ}$. After four hours on the stream bath, the solvent was removed in vacuo from the acidified reaction mixture, and the residue was extracted repeatedly with hot absolute ethanol. The ethanol was removed and the residue recrystallized from chloroform and then from ethanol giving $1.9 \mathrm{~g}(64 \%)$ of colorless crystals, m.p. $61-62^{\circ}$; literature m.p. $54-58^{\circ}$ (Kilmer et al., 1942).

3.4-Diacetoxythiolane.-(a) To $2.5 \mathrm{~g}$ (0.01 mole) of DL-1,4-dichloro-2,3-diacetoxybutane (Owen, 1949) in $100 \mathrm{ml}$ of ethanol was added a solution of $5 \mathrm{~g}$ (0.02 mole) of sodium sulfide nonahydrate in $10 \mathrm{ml}$ of hot ethanol, and the solution was refluxed for five hours. The cooled product was filtered and the filrate concentrated in vacuo to yield a colorless solid which, after recrystallization from petroleum ether $\left(30-60^{\circ}\right)$, gave $1.3 \mathrm{~g}(64 \%)$ of colorless needles, m.p. $42-44^{\circ}$. (b) A mixture of $3.0 \mathrm{~g}$ ( $0.03 \mathrm{~mole})$ of 3,4-dihydroxythiolane, $20.8 \mathrm{~g}$ of acetic anhydride, and $2 \mathrm{ml}$ of hydrochloric acid was refluxed for five hours. The solvent was removed and the residue recrystallized from petroleum ether $\left(30-60^{\circ}\right)$ to give $3.7 \mathrm{~g}(73 \%)$ of colorless needles, m.p. $42-44^{\circ}$.

Anal. Calcd. for $\mathrm{C}_{8} \mathrm{H}_{12} \mathrm{O}_{4} \mathrm{~S}: \mathrm{C}, 47.1 ; \mathrm{H}, 5.9$. Found C, $47.2 \mathrm{H}, 5.8$.

3,4 Dibenzoxythiolane.-To a stirred mixture of $2.4 \mathrm{~g}(0.02 \mathrm{~mole})$ of 3,4 - dihydroxythiolane and $2 \mathrm{~g}(0.05$ mole $)$ of sodium hydroxide as a $20 \%$ aqueous solution at $5^{\circ}$ was slowly added $7 \mathrm{~g}(0.05 \mathrm{~mole})$ of benzoyl chloride. The mixture was refluxed for four hours, cooled, and the crystalline solid which precipitated was extracted with sodium carbonate solution. Recrystallization from petroleum ether $\left(30-60^{\circ}\right)$ gave $5.0 \mathrm{~g}(81 \%)$ of colorless crystals, m.p. 136-137\%.

Anal. Calcd. for $\mathrm{C}_{18} \mathrm{H}_{16} \mathrm{O}_{4} \mathrm{~S}: \mathrm{C}, 65.8 ; \mathrm{H}, 4.8$. Found: C, 65.3; $\mathrm{H}, 4.7$.

3,4-Diethoxythiolane.-Synthesized by the method of Patterson and Karabinos (1946) in $33 \%$ overall yield from butadiene.

\section{DEHYDROGENATIONS}

Liquid phase. The thiolanes were heated with the calculated amount, or a slight excess, of sulfur at temperatures in the range of $120-220^{\circ}$ and for periods of time ranging from fifteen minutes to twenty-six hours. Both with and without a solvent ( $p$-cymene, napthalene), hydrogen sulfide was given off and carbonaceous decomposition products were isolated, except in the runs with short reaction times wherein most of the starting material was recovered unchanged. Platinized charcoal (Linstead and Thomas, 1940) and the thiolanes in refluxing napthalene gave similar results. 3,4-Diacetoxythiolane (1 mole) was recovered unchanged after refluxing with chloranil (2 moles) (Arnold and Collins, 1939) for sixteen hours in benzene. The same result was obtained with the dibenzoxy compound.

Vapor phase. An electrically heated galvanized iron pipe, 5 feet long and 1 inch in diameter, was packed with $1 / 4$ inch fused alumina balls (Alcoa Tabular Alumina T-162; we wish to thank the Aluminum Company of America for the gift of this material). Photomicrographs of these balls show that the surfaces are not porous; the alumina displays no tendency to adsorb simple hydrocarbons or hydrogen (private communication from Dr. H. E. Hoelscher). Two dropping funnels with pressure equalizer side arms, one funnel for a solution of sulfur and the second for the thiolane solution, were connected to the tube by preheaters. The reactor was also fitted with nitrogen inlet, thermocouple, and receiver and condensing system. A solution of $10 \mathrm{~g}$ of the cyclic sulfide (dibenzoxy-or diethoxythiolane) in $100 \mathrm{ml}$. of $m$-xylene or diphenyl ether was introduced through one preheater during the course of two hours, while a solution of $3.5 \mathrm{~g}$ of sulfur in the same solvent was added through the other. The temperature of the reactor 
in different runs varied from $455-525^{\circ}$. The approximate nitrogen flow rate varied from 0.1 to $1.5 \mathrm{ft} 3 /$ minute. In each case decomposition occurred, and no organic product other than the solvent could be isolated. Preliminary runs showed that the solvents and sulfur when passed through the tube severally could be recovered quantitatively. Attempts to prepare thiophene itself by pyrolysis of these thiolanes at temperatures up to $585^{\circ}$ and at the same reaction times as above were unsuccessful, carbonization of the organic sulfur compound occurring. Deposition of a carbon layer on a fresh charge of alumina balls was observed after only one run.

\section{REFERENCES}

Arnold, R. T., and C. J. Collins. 1939. The low temperature dehydrogenation of hydroaromatic rings. Jour. Am. Chem. Soc., 61: 1407.

Fager, E. W. 1945. Some derivatives of 3,4-dihydroxythiophene. Jour. Am. Chem. Soc., 67: 2217.

Friedmann, W. 1941. Action of sulfur upon hydrocarbons under high pressure. Refiner Natural Gasoline Mfr., 20: 395.

Friedmann, W. 1951. Dithionethiophanes. Jour. Inst. Petroleum, 37: 325; cf. Rasmussen, H. E., R. C. Hansford, and A. N. Sachanen, 1946. Reactions of aliphatic hydrocarbons with sulfur. Ind. Eng. Chem., 38: 376.

Friedmann, W. 1951b. Dehydrogenation of tetrahydrothiophene. Jour. Inst. Petroleum, 37: 239 .

Grischkewitsch-Trochimowski, E. 1916. Sulfides with a 5-membered nucleus. Jour. Russ. Phys. Chem. Soc., 48: 901; the thiophene was not isolated but was presumed to be present since the reaction product gave a positive indophenin test.

Jurjew, Y. K., and A. E. Borissow. 1936. Catalytic transformations of heterocyclic compounds. Ber., 69: 1395 .

Kilmer, G. W., M. D. Armstrong, G. B. Brown, and V. du Vigneaud. 1942. Synthesis of a 3,4-diaminotetrahydrothiophene and a comparison of its stability with the diaminocarboxylic acid from biotin. Jour. Biol. Chem., 145: 495.

Linstead, R. P., and S. L. S. Thomas. 1940. Dehydrogenation. Jour. Chem. Soc. 1127 (catalyst- - ).

Mislow, K., and H. M. Hellman. 1951. Stereochemistry of 1,4-addition. Jour. Am. Chem. Soc., $73: 244$.

Morell, S. A., H. H. Geller, and E. C. Lathrop. 1945. Conversion of 2,3-butylene glycol to 1,3-butadiene by pyrolysis of diacetate. Ind. Eng. Chem., 37:877.

Owen, L. N. 1949. The dichlorobutanediols. Jour. Chem. Soc., 241.

Patterson, W. I., and J. V. Karabinos. 1946. Biotin intermediate. U. S. pat. 2,400,436.

Shlechter, N., D. F. Othmer, and R. Brand. 1945. Pyrolysis of 2,4-butylene glycol diacetate to butadiene. Ind. Eng. Chem., 37, 905 (1945).

Turnbull, S. G., Jr. 1948. 3,4-Dihydroxythiophene. U. S. pat. 2,453,103. 